\title{
Correlation between nutritional state, blood pressure and waist circumference in sedentary
}

\section{women}

\begin{abstract}
Introduction: It is well known that blood pressure and cardiovascular damage are related and how cardiovascular mortality is modified by the concomitance of other cardiovascular disease factors.

Objective: The aim of this study was to correlate the nutritional state, blood pressure and waist circumference in sedentary women.

Methods: Descriptive correlational research. The sample consisted of 17 adult women, non-practitioners of physical exercise, who lives in a townhouse in the west zone of Rio de Janeiro City, Brazil. The body composition variables measured were total body mass (BM), height (HT), waist circumference (WC). Body mass index (BMI) was calculated using the anthropometric measures obtained. Systolic and diastolic blood pressure (SBP and DBP) were measured on the day anthropometric measurements were collected using an OMRON HEM-7200 digital electronic sphygmomanometer. The volunteers should be at rest, seat in calm place for 15 minutes. Descriptive and inferential statistics was used, and $p$-value was $95 \%(\mathrm{p}<0,05)$.

Results: It could be observed a significative and positive correlation between nutritional state and systolic and diastolic blood pressure. That means that $37 \%$ of the total variation of SBP and $28 \%$ of the DBP are explained by the BMI in this group. On the other hand, no correlation between waist circumference and blood pressure was observed (WC x SBP: $\mathrm{r}=$ $0.40 ; \mathrm{p}=0.11$ and WC $\mathrm{x}$ DBP: $0.28 ; \mathrm{p}=0.26$ )

Conclusion: Considering the relation between overweight and BP disorders, at this group, there was a significant positive correlation between nutritional state and blood pressure both SBP as well as DBP. So, the BMI is still a reasonably good measure of general adiposity and a significant risk factor for hypertension.
\end{abstract}

Keywords: sedentary behavior, women, risk factors
Volume 9 Issue $6-2019$

\author{
Danielli Mello,' Rodrigo Vale, ${ }^{2,3}$ Marcos \\ Fortes, ${ }^{4}$ Ighor Henriques, ${ }^{6,7}$ Ravini Sodré, ${ }^{6}$ \\ Fábio Gomes Dias, ${ }^{5}$ Tuane Majid Calassara, ${ }^{5}$ \\ Matheus Lincoln Selepengue, ${ }^{5}$ Guilherme \\ Rosa $^{5-7}$ \\ 'Physical Education College of the Brazilian Army (EsEFEx, EB, \\ RJ, Brazil) \\ 2Laboratory of Exercise Physiology (LAFIEX, UNESA, Cabo Frio, \\ RJ, Brazil) \\ ${ }^{3}$ State University of Rio de Janeiro (PPGCEE, IEFD, UERJ, Brazil). \\ ${ }^{4}$ Brazilian Army Research Institute of Physical Fitness (IPCFEx, \\ EB, RJ, Brazil) \\ ${ }^{5}$ Castelo Branco University (UCB, Rio de Janeiro, Brazil) \\ ${ }^{6}$ Research Group in Physical Exercise and Health Promotion \\ (GEPS, RJ, Brazil) \\ ${ }^{7}$ Bezerra de Araújo College (FABA, RJ, Brazil)
}

Correspondence: Danielli Mello, Physical Education College of the Brazilian Army (EsEFEx, EB, Rio de Janeiro), Brazil, Email danielli.mello@gmail.com

Received: October 22, 2019 | Published: November II, 2019
Abbreviations: CVD, cardiovascular disease; BM, body mass; $\mathrm{WC}$, waist circumference; BMI, body mass index

\section{Introduction}

Cardiovascular disease (CVD) is the leading cause of death worldwide. ${ }^{1}$ Individuals with similar body mass index may have distinct metabolic and cardiovascular risk profiles. Susceptibility to obesity-related cardiometabolic complications is not solely mediated by overall body fat mass, but is largely dependent upon individual differences in regional body fat distribution and ability of subcutaneous adipose tissue to expand. ${ }^{2}$ CVD risk factors, incidence and death increases comparing to women in reproductive age to menopaused. And a healthy lifestyle can prevent CVD, but it is unclear which lifestyle factors may help maintain and improve cardiovascular health for women after menopausal transition. ${ }^{3}$ Incident CVD events occurred in more middle-aged men and women in overweight (37\% and $28 \%$, respectively), obese ( $47 \%$ and $39 \%$ ), and morbidly obese $(65 \%$ and $48 \%)$ strata compared with adults in the normal Body Mass Index (BMI) group. ${ }^{4}$

It is well known that blood pressure and cardiovascular damage are related and how cardiovascular mortality is modified by the concomitance of other CVR factors. ${ }^{5}$ And the guidelines of the American College of Sports Medicine presented new evidence on several diagnostic and therapeutic aspects including lifestyle modification to reduce cardiovascular risk (CVR). ${ }^{6}$ So, the aim of this study was to correlate the nutritional state, blood pressure and waist circumference in sedentary women.

\section{Methods}

\section{Design}

Descriptive correlational research.

\section{Sample}

The sample consisted of 17 adult women, non-practitioners of physical exercise, who lives in a townhouse in the west zone of Rio de Janeiro City, Brazil. Inclusion criteria: sedentary women according to American College of Sports Medicine, ${ }^{6}$ age between 25 and 35 years old. Exclusion criteria: non-volunteers to the study and women who practiced any physical active regularly. It was estimated a sample size of 23 individuals who were invited to participate in a physical exercise program. However, six women were excluded from the initial study because they were taking regular walks twice a week.

\section{Ethics}

The participants signed an informed consent document to participate in research involving human subjects in accordance with the Declaration of Helsinki. ${ }^{7}$ The research project was also approved 
by the Ethics Committee in Research Involving Human Beings of Federal University of the State of Rio de Janeiro under protocol number 983.976/15.

\section{Data collection}

\section{Body composition}

The body composition variables measured were total body mass (BM), height (HT), waist circumference (WC). To assess total body mass and height, we used a mechanical balance with capacity of $150 \mathrm{~kg}$ and accuracy of $100 \mathrm{~g}$ and a Filizola ${ }^{\circledR}$ stadiometer (Brazil) respectively. Waist circumference was measured with a Sanny ${ }^{\circledR}$ anthropometric tape (Brazil). The procedures followed International Society for the Advancement of Kinanthropometry (ISAK) guidelines. ${ }^{8}$ Body mass index (BMI) was calculated using the anthropometric measures obtained. BMI was obtained by the ratio of body mass in kilograms to height in meters squared.

\section{Blood pressure}

Systolic and diastolic blood pressure (SBP and DBP) were measured on the day anthropometric measurements were collected using an OMRON HEM-7200 digital electronic sphygmomanometer. The volunteers must be in rest, seat in calm place for 15 minutes.

\section{Statistics}

All the statistical procedures were processed with the Statistical Package for the Social Sciences software (SPSS 18.0, Chicago, USA). The sample size was calculated using the GPower 3.1 statistical program (Frauz Faur Universität Kiel, Germany), using as input an effect size of $0.8, \alpha$ of 0.05 and estimated power of 0.95 . The program estimated a sample size of 23 individuals, but only 17 concluded the physical exercise program. Descriptive statistics were used to establish the mean and standard deviation values. It was used the Shapiro-Wilk (SW) test and as the normality assumption was met, the Pearson Correlation Test was used for inferential analysis. The level of significance applied was $\mathrm{p}<0.05$.

\section{Results}

The sample descriptive characteristics are presented in Table 1. The Figure 1 presented the correlation between the nutritional state and systolic and diastolic blood pressure. It could be observed a significative and positive correlation between nutritional state and systolic and diastolic blood pressure. That means that $37 \%$ of the total variation of SBP and $28 \%$ of the DBP are explained by the BMI in this group. On the other hand, no correlation between waist circumference and blood pressure was observed (WC x SBP: $r=0.40 ; p=0.11$ and WC x DBP: $0.28 ; p=0.26$ ).

Table I Sample descriptive characteristics

\begin{tabular}{|c|c|c|c|c|c|c|c|}
\hline & $\begin{array}{l}\text { Age } \\
\text { (years) }\end{array}$ & TBM (kg) & $\begin{array}{l}\text { Height } \\
\text { (m) }\end{array}$ & $\begin{array}{l}\text { BMI (kg/ } \\
\text { m2) }\end{array}$ & $W C(\mathrm{~cm})$ & $\begin{array}{l}\text { PAS } \\
(\mathrm{mmHg})\end{array}$ & $\begin{array}{l}\text { PAD } \\
(\mathrm{mmHg})\end{array}$ \\
\hline Mean & 30,9 & 78,4 & $\mathrm{I}, 7$ & 28,6 & 86,5 & 129,5 & 78,0 \\
\hline SD & 2,5 & 15,1 & 0,1 & 4,7 & 16,3 & 13,5 & 10,3 \\
\hline Minimum & 27 & 54 & I,54 & 19,13 & 60 & 110 & 63 \\
\hline Maximum & 35 & 106 & $|, 8|$ & 37,97 & 112 & 165 & 91 \\
\hline $\begin{array}{l}\text { SW } \\
\text { (p-value) }\end{array}$ & & & & 0,43 & 0,23 & 0,10 & 0,01 \\
\hline
\end{tabular}

Legend:TBM, total body mass; BMI, body mass index;WC, waist circumference; SBP, systolic blood pressure; DBP, diastolic blood pressure.

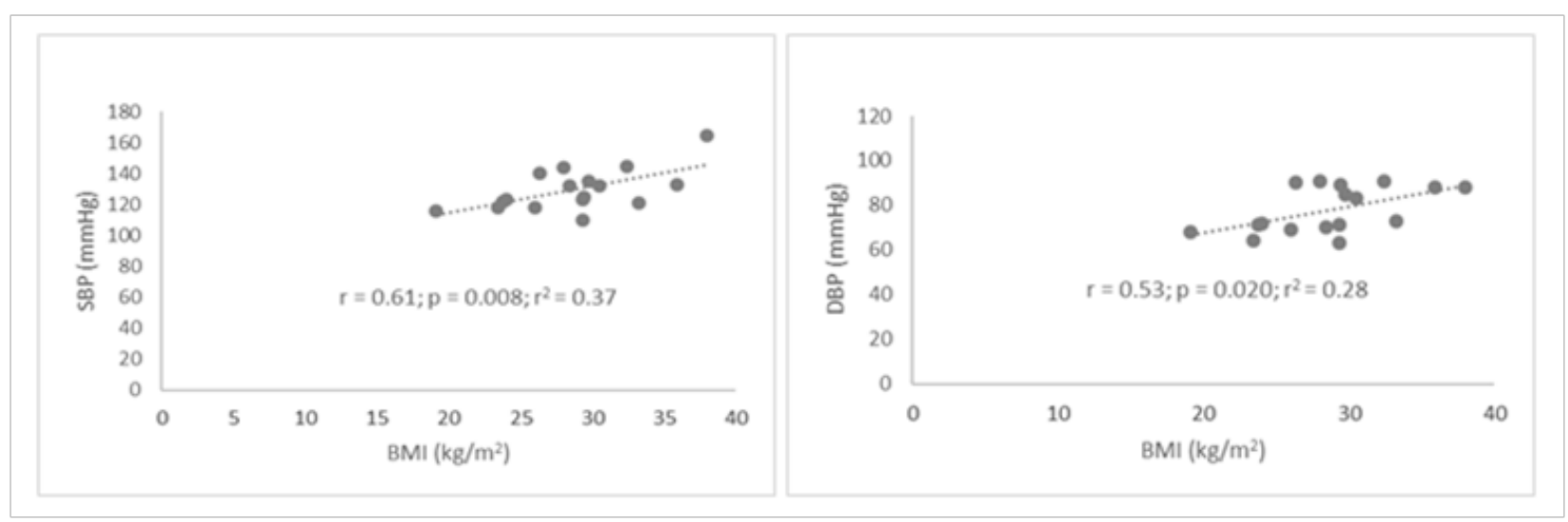

Figure I Correlation between blood pressure and nutritional state. 


\section{Discussion}

Body mass index (BMI) is used as an indicator individual's nutritional status because of its relationship with the risk of mortality and morbidity of chronic diseases. ${ }^{10,11}$ However, it does not provide specific information on adiposity or body fat, ${ }^{12}$ neither differentiate lean mass from fat mass nor fat distribution. It is important to mention that visceral adiposity plays a more important role in the development of insulin resistance and diabetes, than general adiposity, so the use of $\mathrm{BMI}$ as a unique indicator is not recommended.

Confirming this statement, the volunteers in the present study were classified as overweight based on BMI, however, waist circumference measurements do not represent a risk factor, since the maximum recommended value for women is $88 \mathrm{~cm}$ and the volunteers presented an average of $86 \mathrm{~cm} .{ }^{13}$ But the blood pressure values were above the guidelines suggest by American College of Sports Medicine ${ }^{13}$ and American College of Cardiology/American Heart Association. ${ }^{14}$ Data indicate that low cardiorespiratory conditioning (caused by physical inactivity) and excessive accumulation of body fatness (especially visceral), are among the risk factors for the development of metabolic and cardiovascular diseases such as hypertension. ${ }^{13,15}$ In the overall population, the prevalence of hypertension was higher in overweight and obese participants compared to normal-weight subjects. Even if males were 1.9 times more likely to be hypertensive than females. ${ }^{16}$

Timpka et al., ${ }^{17}$ suggests that the risk of chronic hypertension after history of hypertensive disorders of pregnancy might be markedly reduced by adherence to a beneficial lifestyle. ${ }^{17}$ In a cohort study, people with hypertension and diabetes had lower mean healthy lifestyle scores than those without disease. Women with incident hypertension from 2001 to 2011 had lower odds of improving their healthy lifestyle score during this time period compared to those without this disease. ${ }^{18}$ Healthy lifestyles are integral in preventing and treating common cardiovascular and metabolic diseases. So, it was suggested a behavior change and physical activity; promoting a positive health behavior (physical activity) rather than reducing a negative one (sedentary behavior). ${ }^{19}$

\section{Conclusion}

Considering the relation between overweight and BP disorders, although the BMI does not reflect body fat distribution, in this study, there was a significant positive correlation between nutritional state and blood pressure both SBP as well as DBP. BMI is still a reasonably good measure of general adiposity and a significant risk factor for increased risk of many chronic diseases as well as mortality.

\section{Acknowledgements}

None.

\section{Conflict of interests}

Author declares that we have no conflict of interest.

\section{Funding details}

None.

\section{References}

1. WHO. World Health Organization. Global action plan for the prevention and control of noncommunicable diseases 2013-2020. Geneva (Switzerland); 2013.
2. Piché M-E, Poirier P, Lemieux I, et al. Overview of epidemiology and contribution of obesity and body fat distribution to cardiovascular disease: an update. Progin cardiovasc dis. 2018;61(2):103-113.

3. Colpani V, Baena CP, Jaspers L, et al. Lifestyle factors, cardiovascular disease and all-cause mortality in middle-aged and elderly women: a systematic review and meta-analysis. Eur $J$ Epidemiol. 2018;25(14):1485-1495.

4. Khan SS, Khan SS, Ning H, et al. Association of body mass index with lifetime risk of cardiovascular disease and compression of morbidity. JAMA Cardiol. 2018;3(4):280-287.

5. Gheorghe A, Griffiths U, Murphy A, et al. The economic burden of cardiovascular disease and hypertension in low-and middle-income countries: a systematic review. BMC Public Health. 2018;18(1):975.

6. ACSM. American College of Sports Medicine's guidelines for exercise testing and prescription. 10 ed. Philadelphia, PA: Wolters Kluwer Health; 2018.

7. WMA. Declaration of Helsinki. Ethical Principles for Medical Research Involving Human Subjects. 59th WMA General Assembly, Seoul; 2008.

8. Marfell-Jones T, Stewart A, Carter L. International standards for anthropometric assessment. South Africa: International Society for the Advancement of Kinanthropometry; 2006.

9. Godoy-Matos A, Oliveira J, Guedes E, et al. Brazilian obesity guidelines 2009/2010. Brazilian Association for the Study of Obesity and Metabolic Syndrome (ABESO). 2009(3):11-30.

10. Anjos LA. Body mass index (body mass.stature-2) as an indicator of adult nutritional status: literature review. Rev Saúde Públ. 1992;26(6):431436.

11. W.H.O. Facts about overweight and obesity. 2014; n $^{\circ} 311$.

12. Chang $\mathrm{S}-\mathrm{H}$, Beason TS, Hunleth JM, et al. A systematic review of body fat distribution and mortality in older people. Maturitas. 2012;72(3):175-191.

13. ACSM. Guidelines For Exercise Testing and Prescreption. 10th ed. Lippincott Williams \& Wilkins; 2017.

14. Muntner P, Whelton PK, Woodward M, et al. A comparison of the 2017 American College of Cardiology/American Heart Association blood pressure guideline and the 2017 American Diabetes Association diabetes and hypertension position statement for US adults with diabetes. Diabetes Care. 2018;41(11):2322-2329.

15. Garber CE, Blissmer B, Deschenes MR, et al. ACSM: Quantity and Quality of Exercise for Developing and Maintaining Cardiorespiratory, Musculoskeletal, and Neuromotor Fitness in Apparently Healthy Adults: Guidance for Prescribing Exercise. Med Sci Sports Exerc. [Special Communications]. 2011.

16. Papathanasiou G, Zerva E, Zacharis I, et al. Association of high blood pressure with body mass index, smoking and physical activity in healthy young adults. Open Cardiovasc Med J. 2015;9:5-17.

17. Timpka S, Stuart JJ, Tanz LJ, et al. Lifestyle in progression from hypertensive disorders of pregnancy to chronic hypertension in Nurses' Health Study II: observational cohort study. BMJ. 2017;358:j3024.

18. Walther D, Curjuric I, Dratva J, et al. Hypertension, diabetes and lifestyle in the long-term-Results from a swiss population-based cohort. Prev Med. 2017;97:56-61.

19. Lachman M, Lipsitz L, Lubben J, et al. When adults don’t exercise: Behavioral strategies to increase physical activity in sedentary middleaged and older adults. Innovation in aging. 2018;2(1):igy007. 